\title{
Tribological Performance of Graphene-Copper-Iron Composite Coating
}

\author{
Zengrong HU, Xueliang FAN, Shaoxiong GUO \\ School of Rail Transportation \\ Soochow University \\ Suzhou, Jiangsu, China \\ e-mail: zengronghu@126.com,xlfan@suda.edu.cn, guoshaoxiong1998@163.com
}

\author{
Feng CHEN \\ College of Mechanical and Electrical Engineering \\ Nanjing University of Aeronautics and Astronautics \\ Nanjing, China \\ e-mail: fchen0526@ nuaa.edu.cn
}

\author{
Jiale XU \\ School of Mechanical Engineering \\ Jiangsu University \\ Jiangsu, China \\ e-mail: xujiale1989@sina.com
}

\begin{abstract}
Graphene sheets and copper powder were dispersed into Polyvinyl Alcohol (PVA) solution by magnetic stirring, and then pre-coating the mixed solution on the polished AISI4140 substrate. Then laser cladding and laser remelting process were used to fabricated graphene copper and iron composite coating. Microstructures and composition of the composite coating was studied by using Scanning Electron Microscopy (SEM), Energy Dispersive Spectrometer (EDS) and Raman spectroscopy. Raman spectrum, SEM results proved that graphene sheets were dispersed in the composite coating. Vickers hardness test results showed that the composite coating had higher hardness values. With the graphene addition, the tribological performance of the composite coatings became better, and for pure copper iron coating, the average friction coefficient was 0.16 , while for the $10 \%$ graphene copper iron coating, it was reduced to 0.13 .
\end{abstract}

Keywords-graphene; composite coating; copper; tribological performance; laser

\section{INTRODUCTION}

Laser surface treatment had been well developed, especially laser cladding special coatings on the surface of important parts, such as, hydro and thermal power plant components[1], shaft parts[2],etc. Laser cladding wear resistance and anti-corrosion coatings has the advantage of fast, flexible reliable and inexpensive. It was wildly applied in many industrial fields. There are several kinds laser cladding powders, mainly there are Co based powders, $\mathrm{Fe}$ based powders and metal-ceramic powders. Among them, $\mathrm{Fe}$ based powders were very popular for its low price, similar component with ferrous material, better wettability and higher bond strength. In order to improve the wear resistance performance of iron based composite coatings, copper and graphene were added into the coating material.

Graphene (Gr) is a fascinating material, which has a carbon atom formed one layer 2D shape. It has many excellent properties, for example, electric and thermal property [3, 4], Young's modulus and tensile stress [5, 6], and outstanding tribological performance. It was easy to think of taking the advantages of these properties to fabricate special property coatings. In fact much effort had been done in this area [7-9]. Here, graphene copper iron composite coating was fabricated by laser cladding and laser remelting technology. Laser material treatment is a rapid heating and cooling process and it will help graphene sheets survival in the composite coating.

\section{EXPERIMENTS}

\section{A. Materials}

The substrate was AISI 4140 steel plate. The copper powders (average diameter less than $10 \mu \mathrm{m}$, Sigma-Aldrich $\mathrm{Co}$.), and multi-layer $\mathrm{COOH}$ rich graphene sheets (average $\mathrm{X} \& \mathrm{Y}$ dimension less than $2 \mu \mathrm{m}$, Cheap Tubes, Inc.) were used in this experiment as they were received.

\section{B. Laser cladding and remelting experiments}

Copper powder, graphene sheets and PVA were used to make solutions by magnetic stirring. And the AISI 4140 substrate were pre-coated with the previous made solutions by using a dropper. An IPG fiber laser system was used to perform the laser cladding and remelting process at the frequency of $50 \mathrm{kHz}$. Laser cladding process burned the PVA and formed a very thin layer graphene copper coating on the surface of the substrate. Then laser remelting it, and during this laser remelting process substrate materials were mixed into the melting pool and at last, formed graphene copper iron coating. The samples were put into a transparent chamber which filled with $\mathrm{N}_{2}$ gas. The detailed information can be obtained from our previous works [10-12].

\section{Microstructure characterization}

Hitachi S-4800 and S-4700 Field emission SEM was used to study the surface morphology and microstructures. The Raman spectra were obtained by a HORIBA LabRAM HR800 Raman spectrometer (HORIBA Jobin Yvon, NJ, USA). 


\section{Mechanical property testing}

Microhardness of the composite coatings was measured by the Leco M-400-H micro-hardness instrument with $200 \mathrm{~g}$ load and $10 \mathrm{~s}$ holding time. The metallographic polishing machine polished the sample surfaces smooth and flat before the microhardness was measured. All tests were carried out at room temperature in a laboratory environment.

\section{RESULTS AND DISCUSSION}

\section{A. Microstructure of the composite coatings}

Fig.1a and $\mathrm{b}$ are the morphology images of the graphene copper iron composite coating. It can be observed that the samples surface was quite smooth, this means after laser treatment the copper powder was melted with the substrate top layer material and graphene was uniformly distributed into the composite. Fig.1c is sectional SEM image, which shows the sectional surface morphology of the composite coating. It can be seen that the microstructure was not uniform, but the composite layer was bonded with the substrate material well. It had metallurgical bonding, which helps the composite layer performed well during the tribological experiment.

Fig. $1 \mathrm{~d}$ is the whole samples image. It can be noticed from Fig.1d that the laser scanning tracks can be seen clearly on the samples surface, it because the diameter of laser beam was small and also laser remelting process was employed. Generally, the whole areas of these samples were flat and no balling defect. This also helps to get reliable tribological experiment results.
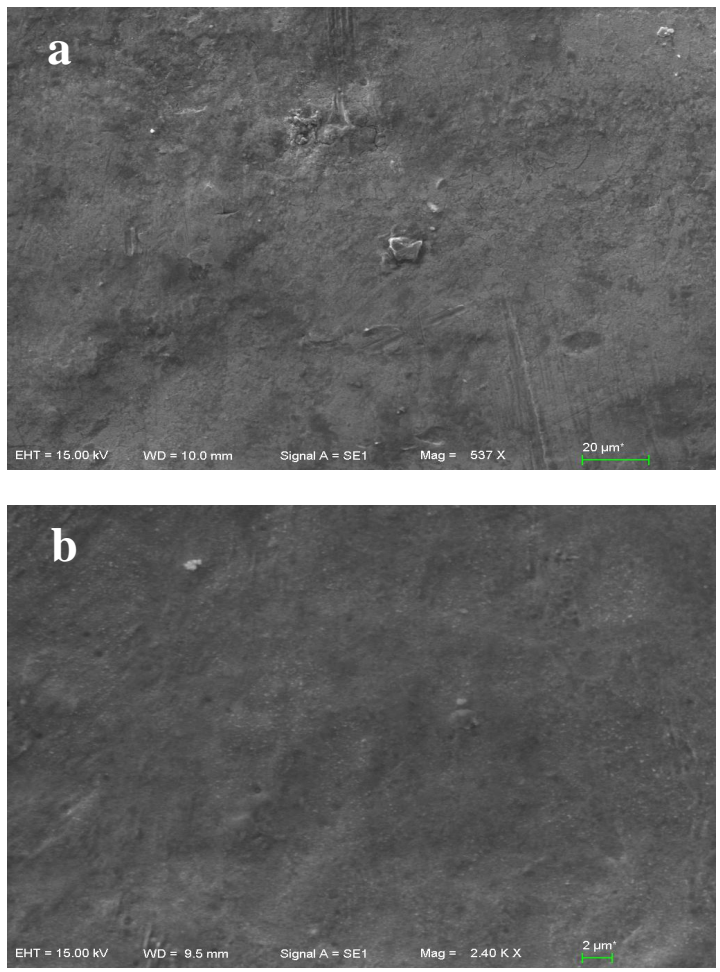
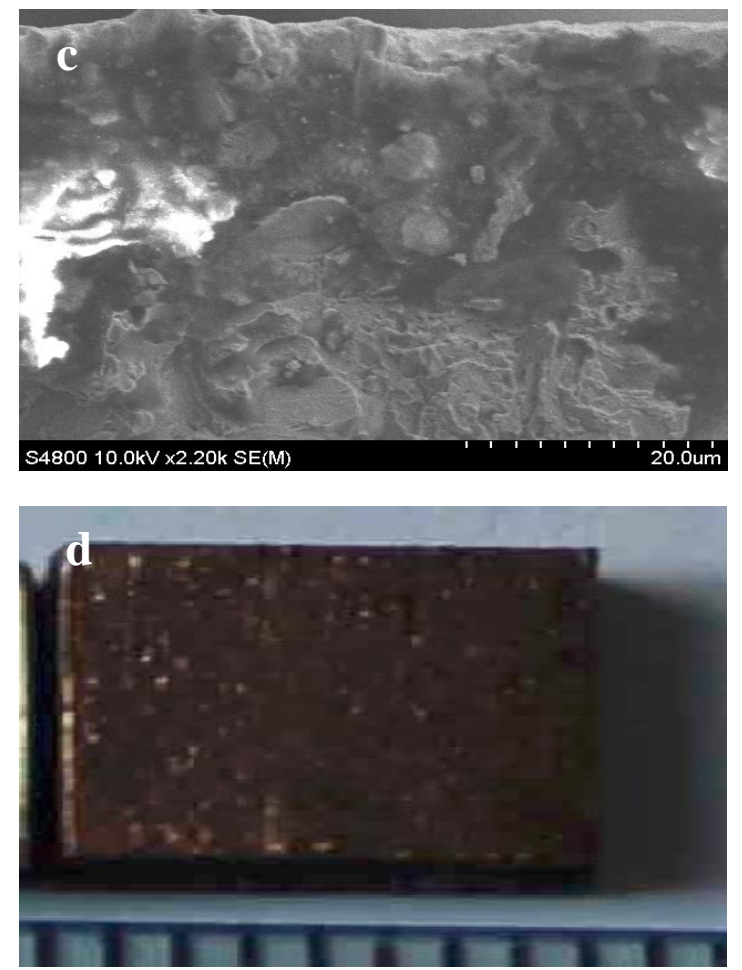

Figure 1. Graphene copper iron composite coating, (a) surface morphology of $\mathrm{Cu}-1 \% \mathrm{Gr}$ sample image, (b) surface morphology of $\mathrm{Cu}$

$10 \% \mathrm{Gr}$, (c) sectional image of $\mathrm{Cu}-5 \% \mathrm{Gr}$, (d) the whole sample.

Fig.2 and Fig. 3 are surface and sectional EDS maps of graphene copper iron composite coatings. Fig.2a is the surface morphology of $1 \mathrm{wt}$. \% graphene content composite coating. Fig. 2b-d is EDS maps of copper, iron, and carbon in the surface layer material. It can be observed form these elements EDS maps, that the component elements were distributed uniformly. Fig.3a is the sectional surface morphology of $5 \mathrm{wt}$. \% graphene content composite coating. Fig. 3b-d is EDS maps of carbon, iron, and copper in the sectional surface layer material. It also can be observed form these elements EDS maps, that the component elements were distributed uniformly. In addition, from Fig.3a, it also can be seen that graphene sheets were appeared on the sectional surface. It proved that after laser treatment graphene sheet still exist in the composite coatings, and it was not destroyed by the high temperature of the laser treatment processes. And our other similar works had been proved that graphene sheets can survive in laser treatment process [11-13].

In fact, the elements were even more uniformly distributed on the element maps after wear and frication experiments. This is reasonable, because in the wear and frication experiments, the steel ball rubbed with the samples surface repeatedly. This will make the components of the surface mixed more uniformly. 
电子圈像 10

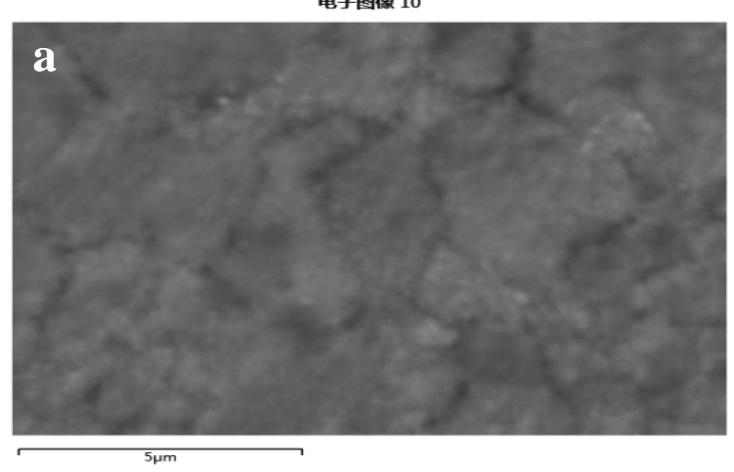

Cu Lo1_2

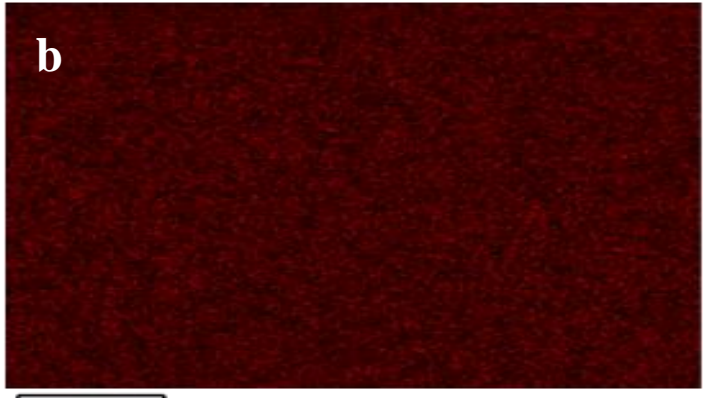

$\longdiv { 1 0 \mu \mathrm { m } }$

Fe $K \alpha 1$

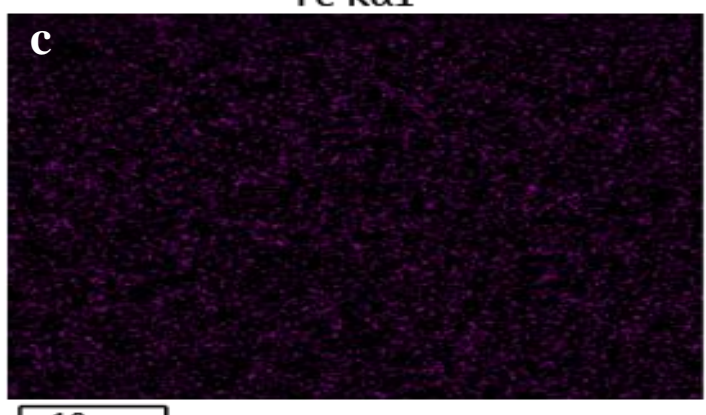

$\longdiv { 1 0 \mu \mathrm { m } }$

C Ka1_2

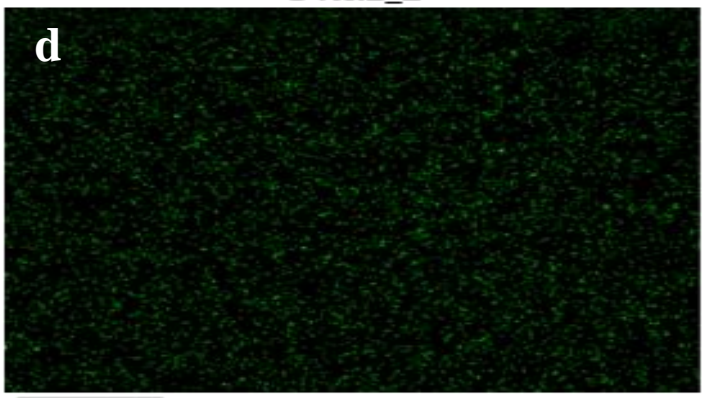

$\longdiv { 1 0 \mu \mathrm { m } }$

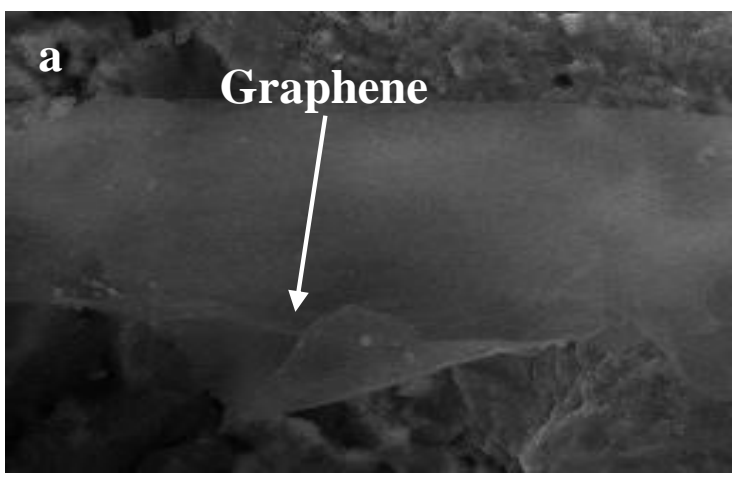

b

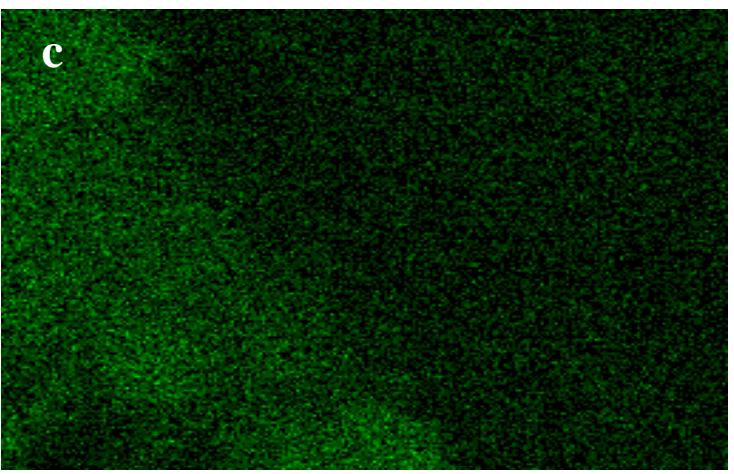

\section{d}

Figure 3. SEM image of cross-section of $10 \% \mathrm{Gr}-\mathrm{Cu}$, (b), (c), and (d) are $\mathrm{C}, \mathrm{Fe}, \mathrm{Cu}$, EDS maps of (a).

Figure 2. (a) SEM image of the surface of $1 \% \mathrm{Gr}-\mathrm{Cu}$, (b), (c), and (d) are $\mathrm{Cu}, \mathrm{Fe}, \mathrm{C}$, EDS maps of (a). 


\section{B. Raman spectrum analysis}

Raman spectroscopy was employed to characterize laser fabricated graphene copper iron composite coatings. Fig. 4 shows the Raman spectra of laser fabricated graphene copper iron composite coatings. It shows the outstanding peaks at $1329.9, \sim 1577.8$ and $\sim 2677.6 \mathrm{~cm}^{-1}$, corresponding to the multilayer grapnene's D peak, G peak and 2D peak, respectively[14, 15]. It was also proved that graphene sheets were survived in the laser fabricating process; and graphene copper iron composite coatings were successfully fabricated.

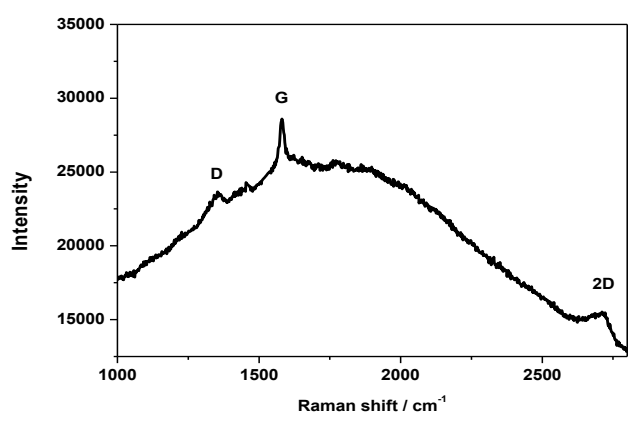

Figure 4. Raman spectrum of graphene copper iron coating layer.

\section{Vickers hardness of the composite coatings}

Different graphene content samples were prepared. There were $0 \%, 0.5$ wt. $\%, 1$ wt. $\%$ and 5 wt. $\%$ and 10 wt. $\%$ samples, which were made with the same technical parameters. Fig. 5 shows the average Vickers hardness values of those samples. It can be noticed that the hardness values were increasing as the graphene content increasing first, and then after a certain graphene content $(5 \mathrm{wt} . \%)$, the hardness values were decreasing. In this project, the highest average value achieved at the 5 wt. $\%$ graphene content samples. The 10 wt. \% graphene content samples have a lower average hardness value. It was due to the aggregation of graphene sheets $[16,17]$. And the error bars of these average hardness values on Fig.5 also illustrated that higher graphene samples hardness values were scattered maybe mainly due to graphene agglomeration.

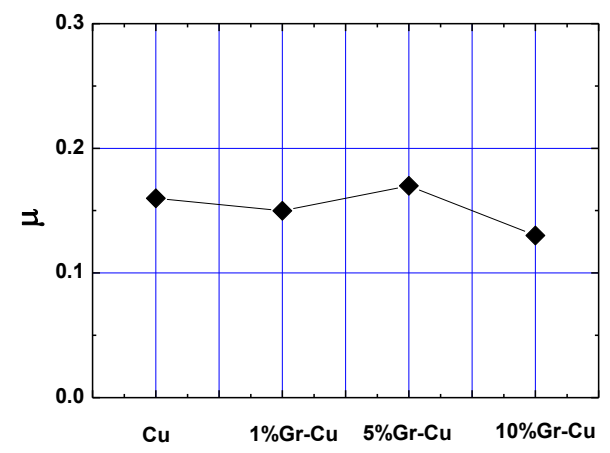

Figure 5. Vickers hardness of graphene copper iron composite coatings.

\section{Wear and frication property}

Fig. 6 shows the low magnification SEM images of the worn surface of different graphene content copper iron composite coatings. It can be observed from those images that the surface morphologies were similar. As shown in Fig. 7, which was high magnification SEM images, all the worn surfaces have a relatively rough morphology. Plastic deformation can be observed on all the worn surface of copper iron and graphene copper iron composite coating. However, as graphene content increasing, abrasive dusts seem decreasing and plastic deformation and adhesive wear and abrasive wear were weakened. Just as it was performed on graphene nickel composites tests[18], the reasons existed in two aspects: the increased hardness of the composites and also graphene sheets act as load bearing and solid lubrication components in the composites.

From Fig. 7d, it can be seen that there were cracks distributed on the worn surface of $10 \%$ Gr composite sample. However, no cracks can be found on the worn surface of other samples. This may be due to the high graphene content. As we know, the density of graphene was very low, for 10 wt. $\%$, the volume fraction will be reach to almost $50 \%$, so graphene was easy to accumulate. Since the interaction force between graphene sheets was weak, and also graphene have a weaker interaction force with copper than that of nickel, when the steel ball rubbed on the Gr-Cu surface, it will form micro cracks on the contacted surface.

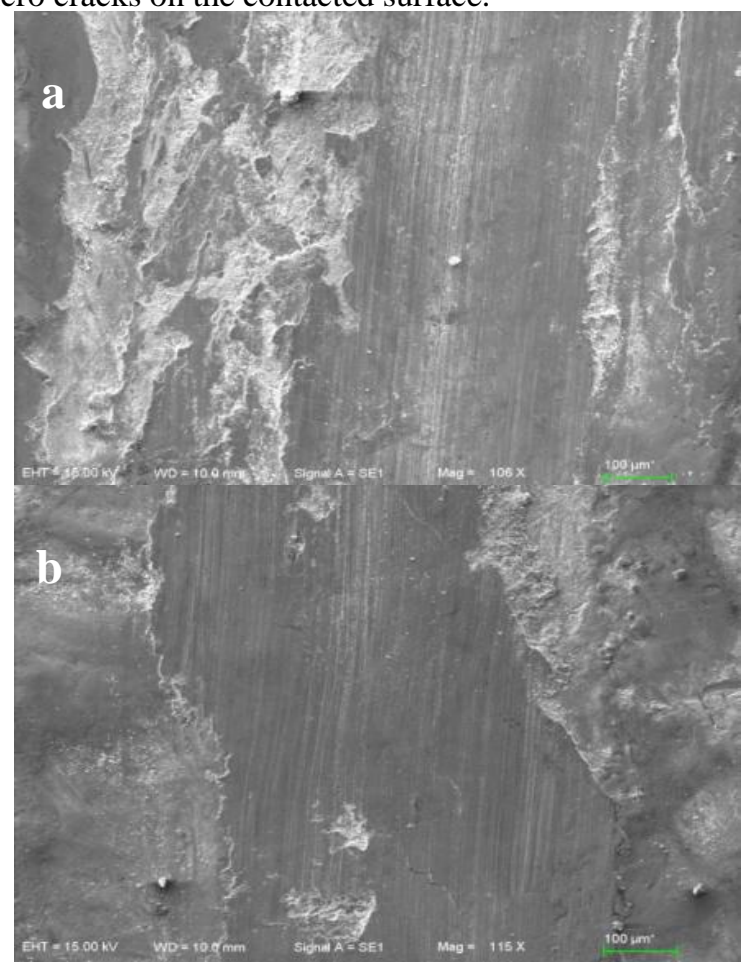




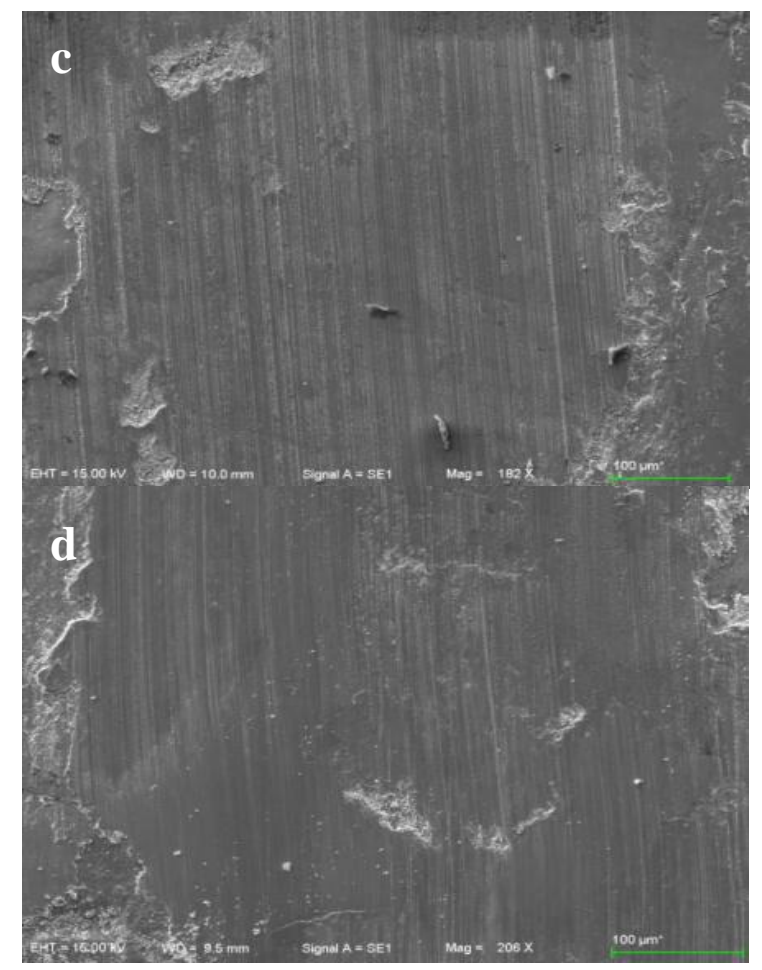

Figure 6. Low magnification SEM morphologies of the wear tracks of graphene copper iron composite coatings with different graphene content; (a) $\mathrm{Cu}$, (b) $1 \% \mathrm{Gr}$, (c) $5 \% \mathrm{Gr}$ and (d) $10 \% \mathrm{Gr}$ at a constant sliding speed of $25 \mathrm{~mm} / \mathrm{s}$ for $5 \mathrm{~min}$.

Fig. 8 shows the average friction coefficients of different graphene content copper iron composite coatings. It can be found that the friction coefficient of the composite coatings have no significant difference. This maybe because the samples surface was oxidized, for it can be seen from Fig. 9 that the EDS spectrum shows high oxygen content in the worn surface.

Moreover, it can be observed that for the friction coefficient of graphene copper iron coatings, the general trend is decreasing as the graphene content increasing. However, the friction coefficient of 5\% graphene copper iron composite coating was an exception. It was a little higher than others. This maybe because of the oxidation and remained burned PVA on the sample surface or there were some experiments errors need further experiments to verify it.

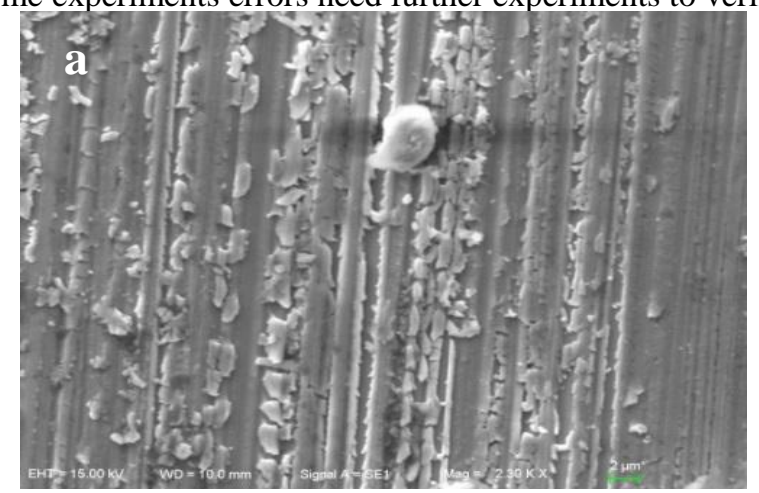

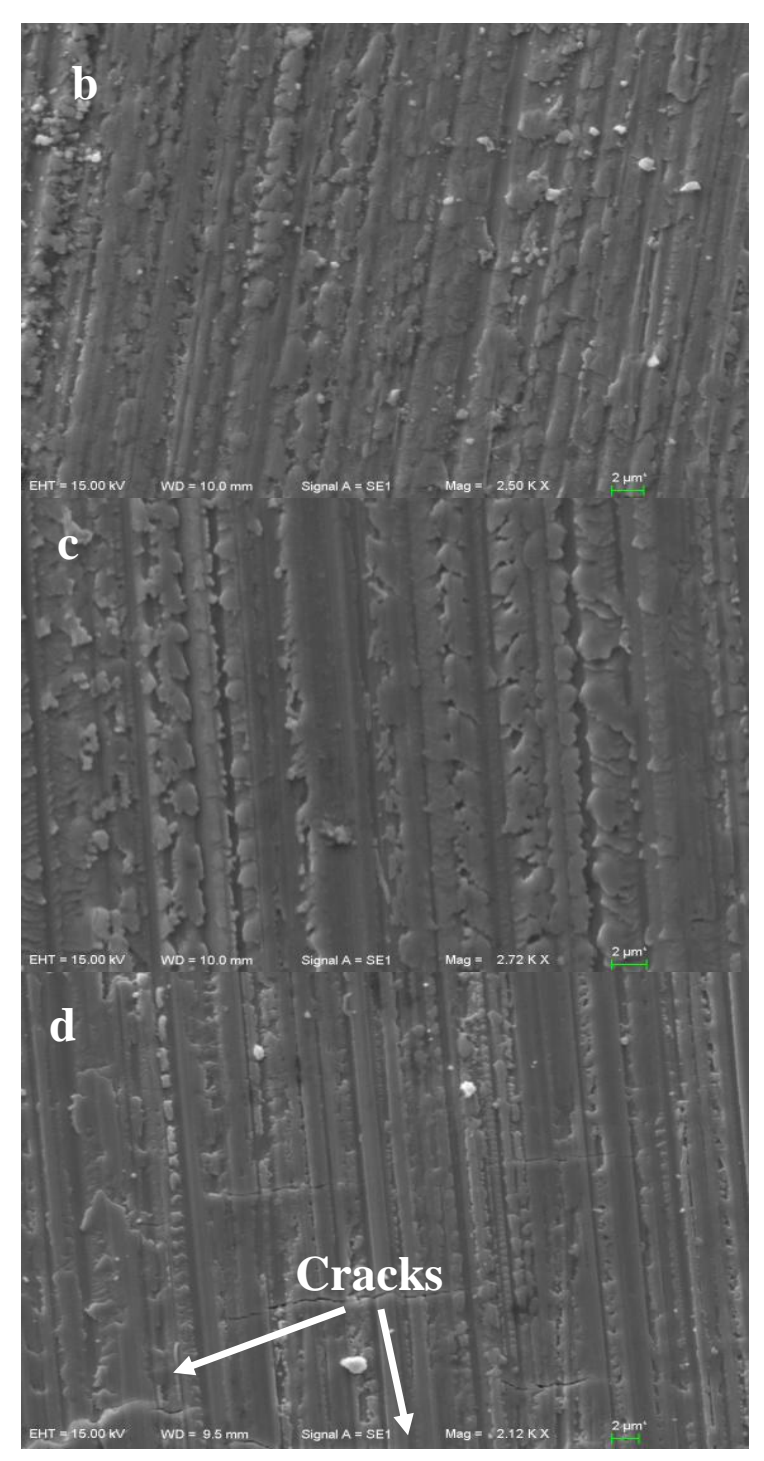

Figure 7. High magnification SEM images of surface morphology of the wear tracks of graphene copper iron composite coatings with different graphene content; (a) Cu, (b) $1 \% \mathrm{Gr}$, (c) $5 \% \mathrm{Gr}$ and (d) $10 \% \mathrm{Gr}$ at a constant sliding speed of $25 \mathrm{~mm} / \mathrm{s}$ for $5 \mathrm{~min}$.

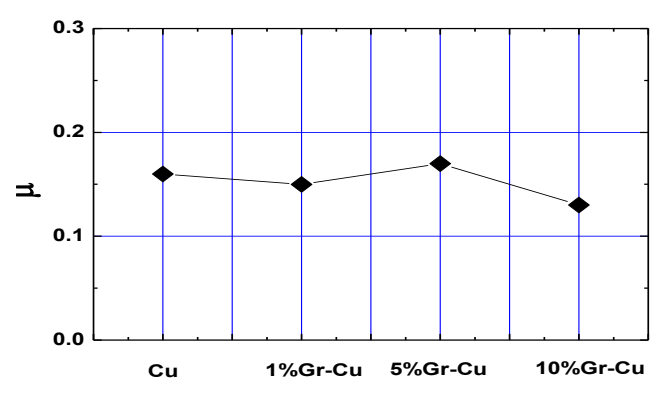

Figure 8. Effect of the graphene content on friction coefficient of graphene copper iron composite coatings 

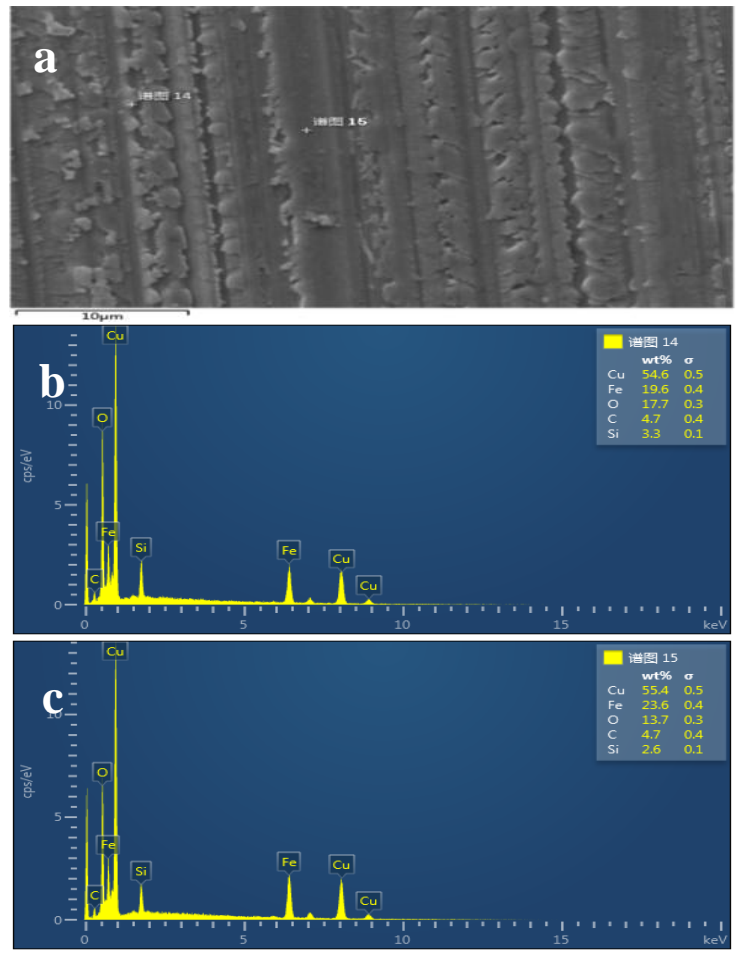

Figure 9. SEM morphology of the wear tracks of 5\% graphene content composite coating, (b) and (c) EDS spectra of the marked points on (a).

\section{CONCLUSION}

0wt. $\%, 1$ wt. $\%, 5$ wt. $\%$ and 10 wt. $\%$ multilayer graphene copper iron composite coatings were prepared by laser cladding and laser remelting on AISI 4140 substrate plates. It was proved by Raman spectrum and SEM images, EDS maps that graphene exist in the laser fabricated graphene copper iron composite coatings. With graphene sheets reinforcement, the composite coatings achieved an improved hardness values. The highest average hardness value is 135 $\mathrm{HV}$ (5wt. \% Gr) and the lowest average hardness value is $100 \mathrm{HV}$. It has a 35\% increase. The wear and friction experiment proved the friction coefficients were greatly reduced with the increase of the graphene reinforcement. And the added graphene sheets can server as load bearing and solid lubrication components in the coating layer [9, 19, 20], this will improve the wear and friction properties of the composite coatings significantly.

\section{REFERENCES}

[1] Mann BS. Laser Surface Treatment of Hydro and Thermal Power Plant Components and Their Coatings: A Review and Recent Findings. J of Materi Eng and Perform. 2015;24(11):4488-502.

[2] Biryukov VP. Wear of a laser-surfaced steel shaft and a slip-bearing bush. Russian Engineering Research. 2015;35(4):249-52.
[3] Novoselov KS, Geim AK, Morozov SV, Jiang D, Zhang Y, Dubonos SV, et al. Electric Field Effect in Atomically Thin Carbon Films. Science. 2004;306(5696):666-9.

[4] Balandin AA, Ghosh S, Bao W, Calizo I, Teweldebrhan D, Miao F, et al. Superior Thermal Conductivity of Single-Layer Graphene. Nano Letters. 2008;8(3):902-7.

[5] Lee C, Wei X, Li Q, Carpick R, Kysar JW, Hone J. Elastic and frictional properties of graphene. physica status solidi (b). 2009;246(11-12):2562-7.

[6] Lee C, Wei X, Kysar JW, Hone J. Measurement of the elastic properties and intrinsic strength of monolayer graphene. Science. 2008;321(5887):385-8.

[7] Algul H, Tokur M, Ozcan S, Uysal M, Cetinkaya T, Akbulut H, et al. The effect of graphene content and sliding speed on the wear mechanism of nickel-graphene nanocomposites. Applied Surface Science. 2015;359:340-8.

[8] Dorri Moghadam A, Omrani E, Menezes PL, Rohatgi PK. Mechanical and tribological properties of self-lubricating metal matrix nanocomposites reinforced by carbon nanotubes (CNTs) and graphene - A review. Composites Part B: Engineering. 2015;77:402-20.

[9] Zhai W, Shi X, Yao J, Ibrahim AMM, Xu Z, Zhu Q, et al. Investigation of mechanical and tribological behaviors of multilayer graphene reinforced Ni3Al matrix composites. Composites Part B: Engineering. 2015;70:149-55.

[10] Hu Z, Tong G. Laser sintered thin layer graphene and cubic boron nitride reinforced nickel matrix nanocomposites. Applied Optics \& Photonics China. Beijing2015. p. 967302--9.

[11] Hu Z, Tong G, Nian Q, Xu R, Saei M, Chen F, et al. Laser sintered single layer graphene oxide reinforced titanium matrix nanocomposites. Composites Part B: Engineering. 2016;93:352-9.

[12] Hu Z, Tong G, Lin D, Nian Q, Shao J, Hu Y, et al. Laser sintered graphene nickel nanocomposites. Journal of Materials Processing Technology. 2016;231:143-50

[13] Zengrong H, Feng C, Dong L, Qiong N, Pedram P, Xing Z, et al Laser additive manufacturing bulk graphene-copper nanocomposites. Nanotechnology. 2017;28(44):445705.

[14] Lee J-K, Lee S, Kim Y-I, Kim J-G, Min B-K, Lee K-I, et al. The seeded growth of graphene. Sci Rep. 2014;4:1-4.

[15] Ferrari AC, Meyer JC, Scardaci V, Casiraghi C, Lazzeri M, Mauri F, et al. Raman Spectrum of Graphene and Graphene Layers. Physical Review Letters. 2006;97(18):187401.

[16] Chu K, Jia C. Enhanced strength in bulk graphene-copper composites. physica status solidi (a). 2014;211(1):184-90.

[17] Ashwath P, Xavior MA. The Effect of Ball Milling \& Reinforcement Percentage on Sintered Samples of Aluminium Alloy Metal Matrix Composites. Procedia Engineering. 2014;97:1027-32.

[18] Hu Z, Shao Z, Chen F, Xu J, Chen C. Wear and Friction Property of Laser Sintered Graphene Nickel Composite Coating. International Conference on Automation, Mechanical Control and Computational Engineering2017.

[19] Li Y, Wang S, Wang Q. Enhancement of tribological properties of polymer composites reinforced by functionalized graphene. Composites Part B: Engineering. 2017;120:83-91.

[20] Li J-f, Zhang L, Xiao J-k, Zhou K-c. Sliding wear behavior of copperbased composites reinforced with graphene nanosheets and graphite. Transactions of Nonferrous Metals Society of China. 2015;25(10):3354-62. 